\title{
FINTECH E O DIREITO DO CONSUMIDOR
}

\section{Rafael Pereira Lima ${ }^{1}$ Daniel Barile da Silveira ${ }^{2}$}

\section{RESUMO}

A proposta do trabalho tem como objetivo uma análise sobre as Fintechs e seu ambiente virtual ensejador de controvérsias estabelecidos a respeito da relação de consumo virtual, o qual estão relacionados ao mecanismo e meio, pelo qual a relação jurídica se efetiva - internet e softwares $\mathrm{O}$ rápido avanço tecnológico não refletiu a efetiva regulamentação da matéria e sobretudo um desenvolvimento jurisprudencial. Para o estudo foi adotado o sistema de referência baseado na teoria dos princípios de Humberto Ávila o método de abordagem científica foi o dedutivo e dialético que se desenvolveu através do procedimento histórico e o funcionalista.

Palavras-chave: Fintech; Internet; Proteção ao consumidor; Relação jurídica de consumo; Responsabilidade civil.

\section{FINTECH AND CONSUMER LAW}

\begin{abstract}
The purpose of this work is to analyze the Fintechs and its virtual environment, which provokes established controversies regarding the relation of virtual consumption, which are related to the mechanism and means by which the legal relationship is effective - internet and softwares. rapid technological advance did not reflect the effective regulation of the matter and, above all, a case-law development. For the study was adopted the system of reference based on the theory of principles of Humberto Avila the method of scientific approach was the deductive and dialectic that developed through the historical and functionalist procedure.
\end{abstract}

Keywords: Fintech; Internet; Consumer protection; Legal relationship of consumption; Civil responsability.

\section{Introdução}

O Código de Defesa do Consumidor (Lei 8.078/90), em seus 27 anos de vigência, se mantém eficaz e plenamente aplicável, em direção a um novo desafio, qual seja, as fintechs, para onde se deslocaram os mesmos negócios jurídicos já conhecidos e regulamentados desde outrora na realidade física.

\footnotetext{
1 Mestrando da Universidade de Marília, com área de concentração: Empreendimentos econômicos, desenvolvimento e mudança social. Especialista em direito tributário pela Unitoledo. Advogado. Endereço postal: Rua Gandhi, 252, Higienópolis, CEP 16.010-670, Araçatuba-SP. Endereço eletrônico: rafael@ pereiralimaadvocacia.com.br.

${ }^{2}$ Pós-Doutorando em Democracia e Direitos Humanos - Universidade de Coimbra. Doutor em Direito, Estado e Constituição - Universidade de Brasília (UnB). Advogado e Consultor Jurídico em Direito Público. Professor Universitário. Sítio eletrônico: danielbarile.com.br.
} 
No entanto, considerando-se a complexidade técnica, tecnológica e jurídica, em que esta relação jurídica se efetiva, há peculiaridades na relação de consumo virtual, que exigem uma adequação das normas consumeristas, a fim de garantir, a plena proteção ao consumidor no ambiente virtual.

O presente ensaio tem objetivo nas fintechs e as dificuldades no ambiente virtual ensejadoras de controvérsias e questionamentos estabelecidos a respeito da relação de consumo virtual, o qual estão relacionados aos mecanismos e ao meio, pelos quais, a relação jurídica se efetiva - internet, softwares, equipamentos eletrônicos e informáticos - os quais evoluíram tecnologicamente em espantosa velocidade nessas décadas. Contudo, o avanço não refletiu em efetiva regulamentação legal da matéria, e, sobretudo, no desenvolvimento jurisprudencial.

Para o estudo foi adotado o sistema de referência baseado na teoria dos princípios de Humberto Ávila o método de abordagem científica foi o dedutivo e dialético que se desenvolveu através do procedimento histórico e o funcionalista.

\section{Conceito de Fintech}

As Fintechs são "instituições financeiras" que unem tecnologia e serviços financeiros para realizar todos os serviços que os bancos tradicionais fazem, porém com estrutura mais enxuta e com muito mais tecnologia de ponta.

O termo "fintech" veio da união, da combinação das palavras em inglês "financial" (finanças) e "technology" (tecnologia).

O advogado Lucas de Mello Ribeiro (2017) define as Fintechs da seguinte maneira:

As Fintechs são startups criadas para as áreas de serviços financeiros, sendo que se diferenciam dos bancos tradicionais em razão de seu processo ser fundamentado em tecnologia. Assim, as Fintechs fornecem serviços ou produtos financeiros que melhorem aqueles já ofertados pelos bancos tradicionais.

Noutra ponta, Fábio Almeida Braga, ao discorrer sobre o conceito de fintechs afirma que:

[...] a fusão de meios e recursos ofertados pela indústria de infraestrutura cibernética aos mercados financeiros e de capitais mundo afora. São as chamadas financial Technologies que são diariamente introduzidas no cotidiano de milhões de usuários de serviços e consumidores de produtos financeiros.

O próprio nome é autoexplicativo e resume muito bem essas instituições, porque prestam serviços financeiros como qualquer outra, mas de maneira mais fácil e rápida, e, 
ainda, sem regulação adequada, uma vez que as operações são feitas pela internet.

A Comissão de Valores Mobiliários - CVM (BRASIL, 2016), órgão regulador do mercado de capitais brasileiro, define Fintech como:

[...] a aplicação intensiva de novas tecnologia nos mercados, produtos ou serviços sob a jurisdição da CVM, incluindo, dentre outros, áreas relacionadas a plataformas de financiamento e à distribuição, negociação e pós-negociação de valores mobiliários, tais como: crowdfunding, digital securities, automated advice, distributed ledger technology e high-frequency trading.

O popular aplicativo "Guia Bolso" (GUIA BOLSO), que é uma fintech, em seu site traz uma definição interessante sobre o modelo de negócio, vejamos:

Fintech é toda empresa que se propõe a oferecer serviços relacionados ao seu dinheiro, só que a custos bem mais baixos que os dos bancos, e beneficiando-se do imenso alcance da internet. O destaque da fintech é o nível da sua eficiência: por usar tecnologia de ponta, é capaz de entregar resultados altamente satisfatórios.

"Banking is essential. Banks not" (HORN, 2016). Essa frase ficou famosa porque foi dita por Bill Gates em 1994. Hoje, 23 anos depois, a visão de Gates começa a ficar mais clara para o consumidor em geral. As fintechs em comparação aos Bancos tradicionais são mais especializadas, operam com muita agilidade, transparência, preços mais baixos e oferecem um leque de operações sofisticadas (NAJJARIAN, 2016, p. 2).

Com efeito, o rápido crescimento e a variedade de serviços ancorado na necessidade dos clientes contribuíram para que as fintechs explorassem áreas como meio de pagamentos; gerenciamento financeiro; otimização de "recompensas" de cartões de crédito: "milhas"; empréstimos e negociação de dívidas; investimentos; seguros; eficiência financeira; e bitcoins, por meio da compra, venda e outras transações que utilizam moeda virtual.

Assim, surge um novo desafio para a Defesa do Consumidor, o mundo cibernético, com as fintechs e seus sofisticados softwares e plataformas digitais.

\section{As Fintechs e o Direito do Consumidor}

O movimento de proteção ao consumidor iniciou na Europa com o advento da Revolução Industrial e se consolidou no Liberalismo Econômico, que veio a consagrar o dogma da autonomia da vontade, através da liberdade de contratação e igualdade formal jurídica dos contratantes (NISHIYAMA, 2002, p. 21).

Nesse passo, com as transformações sociais advindas no final do século XIX, e com a crescente massificação dos meios de produção, dá-se o surgimento da denominada sociedade de consumo (mass consumption society), na qual a produção manual dos bens passa 
a ser exceção, pela introdução da mecanização, produção em série etc. (SILVA; DOS SANTOS, 2013, p. 40).

Ocorre que, essa evolução do processo produtivo gerou um aumento progressivo dos riscos gerados aos consumidores, por meio de falhas resultantes desse processo. Nesse cenário, "verifica-se o domínio do crédito, marketing, da publicidade ilícita (abusiva e enganosa), práticas abusivas, cláusulas contratuais abusivas, falta de informação adequada, surgimento dos contratos de adesão" (GRINOVER, 2007, p. 6-7), com isso, o exercício da liberdade contratual era diminuído ou impossibilitado, impondo severas dificuldades de acesso à justiça.

Nesse cenário, no qual apresentava insuficiência dos esquemas tradicionais do direito substancial e processual, que já não mais tutelavam eficazmente novos interesses identificados como coletivos e difusos, e, a impulsão dos movimentos consumeristas, surgem os primeiros regramentos de proteção ao consumidor.

"Não é difícil explicar tão grande dimensão para um fenômeno jurídico totalmente desconhecido no século passado e em boa parte", afirma Ada Pellegrini Grinover e Antônio Herman de Vasconcelos e Benjamin (2007, p. 7), dado que:

[...] o homem do século XX vive em função de um modelo novo de associativismo: a sociedade de consumo (mass consumption Society ou Konsumgesellschaft), caracterizada por um número crescente de produtos e serviços, pelo domínio de crédito e do marketing, assim como pelas dificuldades de acesso à justiça. São esses aspectos que marcam o nascimento e o desenvolvimento do direito do consumidor, como disciplina jurídica autônomo.

No Brasil, o princípio constitucional, a defesa do consumidor (art. 170, V) encontra embasamento em diversos dispositivos da Constituição: Art.5 $5^{\circ}$ XXXII - o Estado promoverá, na forma da lei, a defesa do consumidor; Art. 24, VIII - responsabilidade por dano ao meio ambiente, ao consumidor, a bens e direitos de valor artístico, estético, histórico, turístico e paisagístico; Art. 150, $\S 5^{\circ}$ A lei determinará medidas para que os consumidores sejam esclarecidos acerca dos impostos que incidam sobre mercadorias e serviços; Art. 48 do ADCT - O Congresso Nacional, dentro de cento e vinte dias da promulgação da Constituição, elaborará código de defesa do consumidor; Art. 175, parágrafo único, II: a lei resguarda o direito dos usuários nas concessões e permissões (BRASIL, 1988).

Com isso, a Constituição Federal emprestou ao princípio de defesa do consumidor especial relevo, nesse sentido as colações de Eros Roberto Grau (2001, p. 272-273), verbis:

A par de consubstanciar, a defesa do consumo contemporizada (a regra "acumulai, acumulai” impõe o ditame "consumi, consumi”, agora porém sob proteção jurídica 
de quem consome) - afeta todo o exercício de atividade econômica, inclusive tomada a expressão em sentido amplo, como se apura da leitura do parágrafo único, II do art. 175. O caráter constitucional conformador da ordem econômica, deste como dos demais princípios de que tenho cogitado, é inquestionável.

Mais a mais, o ensinamento do Professor Luís Roberto Barroso (2001, p. 33), de que “os princípios constitucionais, portanto explícitos ou não, passam a ser a síntese dos valores abrigados no ordenamento jurídico", dado que "espelham a ideologia da sociedade, seus postulados básicos, seus fins", pelo que "dão unidade e harmonia ao sistema, integrando suas diferentes partes e atenuando tensões normativas", e porque os princípios, ademais, condensam valores, dão unidade ao sistema e condicionam a atividade do intérprete.

Essa perspectiva consolidou com o advento do Código de Defesa do Consumidor (Lei 8.078/90), que positivou a proteção ao consumidor de forma específica, e assegurou direitos individuais e coletivos, através da introdução de princípios contratuais, norteados pela sistemática dos preceitos constitucionais e pela concepção social de contrato esculpida na nova teoria contratual.

Assim, temos o Código de Defesa do Consumidor como "uma sobrestrutura jurídica multidisciplinar, aplicável em toda e qualquer área do direito onde ocorrer uma relação de consumo" (RÊGO; RÊGO, 2002), haja vista a dimensão coletiva que assume, bem como sua composição com normas de ordem pública e de interesse social.

Enfim, o Código de Defesa do Consumidor destaca-se como fonte renovadora da teoria dos contratos, pois é reflexo de uma concepção social do contrato, no qual a vontade das partes não é mais a única fonte das obrigações, mas, sobretudo os princípios constitucionais, que migram para o direito privado, e determinam uma nova perspectiva interpretativa do direito contratual (SILVA; DOS SANTOS, 2013, p. 40).

\subsection{A Relação Jurídica de Consumo}

A relação jurídica de consumo é construída pela dinâmica de dois personagens o fornecedor e consumidor em lados opostos, tendo como seu liame o produto ou serviço.

Nesse passo os artigos $2^{\circ}$ e $3^{\circ}$ do Código de Defesa do Consumidor determinam o conceito de consumidor e fornecedor, vejamos:

Art. $2^{\circ}$ Consumidor é toda pessoa física ou jurídica que adquire ou utiliza produto ou serviço como destinatário final.

Parágrafo único. Equipara-se a consumidor a coletividade de pessoas, ainda que indetermináveis, que haja intervindo nas relações de consumo. 
Art. $3^{\circ}$ Fornecedor é toda pessoa física ou jurídica, pública ou privada, nacional ou estrangeira, bem como os entes despersonalizados, que desenvolvem atividade de produção, montagem, criação, construção, transformação, importação, exportação, distribuição ou comercialização de produtos ou prestação de serviços. (BRASIL, 1990)

Neste contexto tecnológico, Claudia Lima Marques (2004, p. 61-63, grifos da autora)

traz novas concepções a respeito dos protagonistas da relação de consumo:

O sujeito fornecedor agora é um ofertante profissional automatizado e globalizado, presente em uma cadeia sem fim de intermediários (portal, website, link, provider, empresas de cartão de cré- dito, etc.), um fornecedor sem sede e sem tempo (a oferta é permanente, no espaço privado e no público), um fornecedor que fala todas as línguas ou usa a língua franca, o inglês, e utiliza-se da linguagem virtual (imagens, sons, textos em janelas, textos interativos, ícones, etc.) para marketing, negociação e contratação.

O sujeito consumidor é agora um destinatário final contratante (art. $2^{\circ}$ do CDC), um sujeito "mudo" na frente de um écran, em qualquer tempo, em qual- quer língua, com qualquer idade, identificado por uma senha (PIN), uma assinatura eletrônica (chaves-públicas e privadas), por um número de cartão de crédito ou por impressões biométricas, é uma coletividade de pessoas, que intervém na relação de consumo (por exemplo, recebendo o compact disc (CD) de presente, comprado por meio eletrônico, ou o grupo de crianças que está vendo o filme baixado por Internet, ex vi parágrafo único do art. $2^{\circ}$ do $\mathrm{CDC}$ ) ou a coletividade afetada por um spam ou marketing agressivo (art. 29 do CDC) ou todas as vítimas de um fato do serviço do provedor de conteúdo, que enviou um vírus "destruidor" por sua comunicação semanal, ou todas as pessoas cujos números da conta corrente ou do cartão de crédito e senha foram descobertos pelo hacker ou cracker que atacou o computador principal do ser- viço financeiro, ou do fornecedor de livros eletrônicos (e-books) art. 17 do CDC.

Ademais, o liame da relação de consumo, os produtos e serviços, que são postos à disposição do consumidor são definidos no artigo $3^{\circ}$, parágrafos $1^{\circ}$ e $2^{\circ}$ do $\mathrm{CDC}$, verbis:

$\S 1^{\circ}$ Produto é qualquer bem, móvel ou imóvel, material ou imaterial.

$\S 2^{\circ}$ Serviço é qualquer atividade fornecida no mercado de consumo, mediante remuneração, inclusive as de natureza bancária, financeira, de crédito e securitária, salvo as decorrentes das relações de caráter trabalhista. (BRASIL, 1990)

A questão a saber é se a relação jurídica entre a Fintech e seu cliente deve se ater ao

Código de Defesa do Consumidor, ou, a questão resta guarida no Sistema Financeiro Nacional, inscrito no art. 192 da Constituição Federal, o qual é disciplinado por lei própria.

Em que pese não haver uma regulamentação jurídica própria sobre fintech, bem como de todas as ramificações de seus serviços, aqui incluem-se bancários, financeiros e de mercado de capitais, as fintechs, em regra, devem ser tratadas como Instituições Financeiras, assim devem continência ao Código de Defesa do Consumidor.

Ademais, a existência de um Código de Defesa do Consumidor, com incidência nas relações entre instituições financeiras e consumidores, não subtrai ao Banco Central o ônus de disciplinar a prestação de serviços das fintechs a clientes e ao público em geral. 
A polêmica foi muito bem asseverada e não passou despercebida pelo Supremo

Tribunal Federal, na Ação Direta de Inconstitucionalidade n. ${ }^{\circ}$ 2591, de relatoria do Ministro

Carlos Velloso, segue ementa:

CÓDIGO DE DEFESA DO CONSUMIDOR. ART. 5o, XXXII, DA CB/88. ART. $170, \mathrm{~V}, \mathrm{DA} \mathrm{CB} / 88$. INSTITUIÇÕES FINANCEIRAS. SUJEIÇÃO DELAS AO CÓDIGO DE DEFESA DO CONSUMIDOR, EXCLUÍDAS DE SUA ABRANGÊNCIA A DEFINIÇÃO DO CUSTO DAS OPERAÇÕES ATIVAS E A REMUNERAÇÃO DAS OPERAÇÕES PASSIVAS PRATICADAS NA EXPLORAÇÃO DA INTERMEDIAÇÃO DE DINHEIRO NA ECONOMIA [ART. $3^{\circ}, \S 2^{\circ}$, DO CDC]. MOEDA E TAXA DE JUROS. DEVER-PODER DO BANCO CENTRAL DO BRASIL. SUJEIÇÃO AO CÓDIGO CIVIL.

1. As instituições financeiras estão, todas elas, alcançadas pela incidência das normas veiculadas pelo Código de Defesa do Consumidor.

2. "Consumidor", para os efeitos do Código de Defesa do Consumidor, é toda pessoa física ou jurídica que utiliza, como destinatário final, atividade bancária, financeira e de crédito.

3. O preceito veiculado pelo art. $3^{\circ}, \S 2^{\circ}$, do Código de Defesa do Consumidor deve ser interpretado em coerência com a Constituição, o que importa em que o custo das operações ativas e a remuneração das operações passivas praticadas por instituições financeiras na exploração da intermediação de dinheiro na economia estejam excluídas da sua abrangência.

4. Ao Conselho Monetário Nacional incumbe a fixação, desde a perspectiva macroeconômica, da taxa base de juros praticável no mercado financeiro.

5. O Banco Central do Brasil está vinculado pelo dever-poder de fiscalizar as instituições financeiras, em especial na estipulação contratual das taxas de juros por elas praticadas no desempenho da intermediação de dinheiro na economia.

6. Ação direta julgada improcedente, afastando-se a exegese que submete às normas do Código de Defesa do Consumidor [Lei n. 8.078/90] a definição do custo das operações ativas e da remuneração das operações passivas praticadas por instituições financeiras no desempenho da intermediação de dinheiro na economia, sem prejuízo do controle, pelo Banco Central do Brasil, e do controle e revisão, pelo Poder Judiciário, nos termos do disposto no Código Civil, em cada caso, de eventual abusividade, onerosidade excessiva ou outras distorções na composição contratual da taxa de juros.

ART. 192, DA CB/88. NORMA-OBJETIVO. EXIGÊNCIA DE LEI COMPLEMENTAR EXCLUSIVAMENTE PARA A REGULAMENTAÇÃO DO SISTEMA FINANCEIRO.

7. O preceito veiculado pelo art. 192 da Constituição do Brasil consubstancia normaobjetivo que estabelece os fins a serem perseguidos pelo sistema financeiro nacional, a promoção do desenvolvimento equilibrado do País e a realização dos interesses da coletividade.

8. A exigência de lei complementar veiculada pelo art. 192 da Constituição abrange exclusivamente a regulamentação da estrutura do sistema financeiro.

CONSELHO MONETÁRIO NACIONAL. ART. 4², VIII, DA LEI N. 4.595/64. CAPACIDADE NORMATIVA ATINENTE À CONSTITUIÇÃO, FUNCIONAMENTO E FISCALIZAÇÃO DAS INSTITUIÇÕES FINANCEIRAS. ILEGALIDADE DE RESOLUÇÕES QUE EXCEDEM ESSA MATÉRIA.

9. O Conselho Monetário Nacional é titular de capacidade normativa --- a chamada capacidade normativa de conjuntura --- no exercício da qual the incumbe regular, além da constituição e fiscalização, o funcionamento das instituições financeiras, isto é, o desempenho de suas atividades no plano do sistema financeiro.

10. Tudo o quanto exceda esse desempenho não pode ser objeto de regulação por ato normativo produzido pelo Conselho Monetário Nacional. 
11. A produção de atos normativos pelo Conselho Monetário Nacional, quando não respeitem ao funcionamento das instituições financeiras, é abusiva, consubstanciando afronta à legalidade.

/\#

- Embargos

/\#

EMENTA: EMBARGOS DE DECLARAÇÃO. LEGITIMIDADE RECURSAL LIMITADA ÀS PARTES. NÃO CABIMENTO DE RECURSO INTERPOSTO POR AMICI CURIAE. EMBARGOS DE DECLARAÇÃO OPOSTOS PELO PROCURADOR GERAL DA REPÚBLICA CONHECIDOS. ALEGAÇÃO DE CONTRADIÇÃO. ALTERAÇÃO DA EMENTA DO JULGADO. RESTRIÇÃO. EMBARGOS PROVIDOS.

1. Embargos de declaração opostos pelo Procurador Geral da República, pelo Instituto Brasileiro de Política e Direito do Consumidor - BRASILCON e pelo Instituto Brasileiro de Defesa do Consumidor - IDEC. As duas últimas são instituições que ingressaram no feito na qualidade de amici curiae.

2. Entidades que participam na qualidade de amicus curiae dos processos objetivos de controle de constitucionalidade, não possuem legitimidade para recorrer, ainda que aportem aos autos informações relevantes ou dados técnicos. Decisões monocráticas no mesmo sentido.

3. Não conhecimento dos embargos de declaração interpostos pelo BRASILCON e pelo IDEC.

4. Embargos opostos pelo Procurador Geral da República.

Contradição entre a parte dispositiva da ementa e os votos proferidos, o voto condutor e os demais que compõem o acórdão.

5. Embargos de declaração providos para reduzir o teor da ementa referente ao julgamento da Ação Direta de Inconstitucionalidade n. 2.591, que passa a ter o seguinte conteúdo, dela excluídos enunciados em relação aos quais não há consenso: ART. $3^{\circ}, \S 2^{\circ}$, DO CDC. CÓDIGO DE DEFESA DO CONSUMIDOR. ART. 5o, XXXII, DA CB/88. ART. 170, V, DA CB/88. INSTITUIÇÕES FINANCEIRAS. SUJEIÇÃO DELAS AO CÓDIGO DE DEFESA DO CONSUMIDOR. AÇÃO DIRETA DE INCONSTITUCIONALIDADE JULGADA IMPROCEDENTE.

1. As instituições financeiras estão, todas elas, alcançadas pela incidência das normas veiculadas pelo Código de Defesa do Consumidor.

2. "Consumidor", para os efeitos do Código de Defesa do Consumidor, é toda pessoa física ou jurídica que utiliza, como destinatário final, atividade bancária, financeira e de crédito.

3. Ação direta julgada improcedente. (BRASIL, 2001)

Desse modo, em síntese, a defesa do consumidor constitui princípio constitucional, que se realiza mediante a aplicação do Código de Defesa do Consumidor. Esse diploma legal não interfere com o Sistema Financeiro Nacional, art. 192 da Constituição, em termos institucionais.

Atualmente, o Sistema Financeiro Nacional é regulado pela Lei n. 4.595/64, recebida pela Constituição como lei complementar naquilo em que ela regula e disciplina o Sistema, não existindo entre aquela Lei e a Lei n. 8.078, de 1990 - Código de Defesa do Consumidor antinomias.

O Código de Defesa do Consumidor sempre será aplicado no que couber, o Código Civil, o Código Comercial, o Código Tributário Nacional, a Consolidação das Leis Trabalhistas e tantas outras leis. 
No mais, o Código de Defesa do Consumidor é norma de ordem pública e interesse social, nos termos do artigo $1^{\circ}$ : "O presente Código estabelece normas de proteção e defesa do consumidor, de ordem pública e interesse social, nos termos dos arts. $5^{\circ}$, inciso XXXII, 170, inciso V, da Constituição Federal e art. 48 de suas Disposições Transitórias" (BRASIL, 1990).

Desta senda, "as normas de ordem pública estabelecem valores básicos e fundamentais de nossa ordem jurídica, são normas de direito privado, mas de forte interesse público, daí serem indisponíveis e inafastáveis através de contratos" (BENJAMIN; MARQUES; BESSA, 2008, p. 55).

Portanto, quando da negociação fintech e cliente estabelecer uma relação de consumo não se pode afastar as normas protetivas do direito do consumidor.

\subsection{Os Princípios do Direito do Consumidor Aplicáveis}

A legislação consumerista, e em especial, o Código de Defesa do Consumidor, estabeleceu amplo rol de institutos do Direito e seus princípios e garantias para a proteção do consumidor e da relação de consumo harmonizada.

Na definição de Humberto Ávila (2005, p. 26), princípios são:

[...] como deveres de otimização aplicáveis em vários graus segundo as possibilidades normativas e fáticas: normativas, porque a aplicação dos princípios depende dos princípios e regras que a eles se contrapõem; fáticas, porque o conteúdo dos princípios como normas de conduta só pode ser determinado quando diante dos fatos.

Para Robert Alexy (2014, p. 26), os princípios jurídicos consistem apenas em uma espécie de normas jurídicas por meio da qual são estabelecidos deveres de otimização aplicáveis em vários graus, segundo as possibilidades normativas e fáticas.

A abordagem principiológica justifica-se em virtude da ausência de legislação própria, bem como da característica da sociedade contemporânea e o meio utilizado pelas fintechs, no qual “[...] o consumidor/usuário experimenta neste mundo livre, veloz e global (relembre-se aqui o consumo pela internet, pela televisão, pelo celular, pelos novos tipos de computadores, cartões e chips), uma nova vulnerabilidade" (BENJAMIN; MARQUES; BESSA, 2008, p. 77).

Logo, no contexto da relação de consumo estabelecida com as fintechs, ater-se-á especificamente naqueles dispositivos, princípios e direitos que lhe são correlatos. 


\subsubsection{Princípio da boa-fé objetiva}

O princípio da boa-fé objetiva apresenta-se na contemporaneidade como regramento vital do Código de Defesa do Consumidor, representando um dos mais importantes princípios do direito privado.

O princípio encontra-se positivado tanto no Código de Defesa do Consumidor (artigo $4^{\circ}$, III e 51, IV, CDC) quanto no Código Civil de 2002 (artigos 113, 187 e 422), que conferiu grande relevância à boa-fé objetiva no direito contratual.

A boa-fé objetiva constitui regra de conduta, de comportamento ético, com lealdade, imposta a todas às partes nas fases do negócio, pautada nos ideais de honestidade, retidão e lealdade, no intuito de não frustrar a legítima confiança, expectativa da outra parte, tendo ainda, a finalidade de estabelecer o equilíbrio nas relações jurídicas (ROSENVALD, 2005, p. $80)$.

Na definição de Claudia Lima Marques, Herman Benjamin e Bruno Miragem, "boafé é cooperação e respeito, é conduta esperada e leal, tutelada em todas as relações sociais" (MARQUES; BENJAMIN; MIRAGEM, 2010, p. 125).

Para Leonardo de Medeiros Garcia (2008, p. 41), a boa-fé objetiva traduz:

[...] um conjunto de padrões éticos de comportamento, aferíveis objetivamente, que devem ser seguidos pelas partes contratantes em todas as fases da existência da relação contratual, desde a sua criação, durante o período de cumprimento e, até mesmo, após a sua extinção.

Bruno Pandori Giancoli e Marco Antônio Araújo Júnior (2009) definem o princípio da boa-fé objetiva como a forma de indicação do comportamento adequado aos padrões de ética, lealdade, honestidade e colaboração, exigíveis nas relações de consumo, desvinculandose, assim, das intenções íntimas do sujeito.

Posto isso, nota-se que o princípio da boa-fé objetiva desvincula-se do caráter subjetivo da conduta, vindo a ser a exigência de um comportamento recíproco entre as partes durante a realização de um negócio, que se relaciona diretamente com os deveres inerentes a qualquer negócio, sem a necessidade de previsão no instrumento.

Claudia Lima Marques, Herman Benjamin e Bruno Miragem (2010, p. 125) ainda trazem as três funções básicas da boa-fé objetiva:

$\left.1^{a}\right)$ Servir como fonte de novos deveres especiais de conduta durante o vínculo contratual, os denominados deveres anexos (função criadora); 
$2^{\text {a }) ~ C o n s t i t u i r ~ u m a ~ c a u s a ~ l i m i t a d o r a ~ d o ~ e x e r c i ́ c i o, ~ a n t e s ~ l i ́ c i t o, ~ h o j e ~ a b u s i v o, ~ d o s ~}$ direitos subjetivos (função limitadora);

$3^{\text {a) }}$ Ser utilizada como concreção e interpretação dos contratos (função interpretadora).

Assim, evidenciada a finalidade trazida pelo princípio da boa-fé objetiva na esfera do direito do consumidor, que é a preservação dos direitos através da exigência de uma conduta dotada de respeito e lealdade por ambas as partes em todas as fases do negócio jurídico.

Desta feita, nota-se que a boa-fé objetiva traz uma ideia de equilíbrio negocial, o que deve ser mantido em todas as fases do negócio jurídico, especialmente nas que envolvam fintech, haja vista que em virtude do ambiente virtual e o objeto, recursos financeiros, o consumidor visivelmente encontra-se em posição de vulnerabilidade.

\subsubsection{Princípio da Informação}

O princípio da informação atribui as partes o dever jurídico de reciprocamente apresentarem todas as circunstâncias relevantes sobre o contrato, desde a fase pré-contratual até a fase pós-contratual, a fim de que os contratantes possam, livremente, exercitar sua autonomia em consonância com os preceitos estabelecidos pela boa-fé objetiva.

Para a Constituição Federal, existem três tipos de direito de informação, sendo eles o direito de informar, direito de se informar e o direito de ser informado.

No âmbito das relações de consumo, o direito à informação, esculpido no artigo $6^{\circ}$, III, CDC, em consonância com o princípio da informação, expresso no artigo $4^{\circ}, \mathrm{IV}, \mathrm{CDC}$, estabelece a obrigatoriedade da informação, dentre os direitos básicos do consumidor, com isso, constitui dever fundamental a prestação de informação clara e adequada pelo fornecedor, dos produtos/serviços fornecidos.

Segundo o doutrinador Flávio Tartucce (2007, p. 141):

[...] a informação, nesse âmbito da ciência jurídica, tem dupla face: o dever de informar e o direito de ser informado, sendo o primeiro relacionado com quem oferece o seu produto ou serviço ao mercado; e o segundo, com o consumidor vulnerável.

Com isso, temos que a fintech deve prestar todas as informações acerca do produto e do serviço colocado no mercado de consumo, frisando bem as características, serviços, riscos, preços, de maneira totalmente clara e precisa, não sendo admitido qualquer falha ou omissão. 
Para o professor Rizzato Nunes (2015, p. 217), “A informação passou a ser componente necessário do produto e do serviço, que não podem ser oferecidos no mercado sem ela".

Nos dias atuais, em que as negociações podem ser realizadas em ambiente virtual, o contrato é informação, por isso a relevância de sua interpretação sempre a favor do contratante mais fraco e de suas expectativas. Neste momento, o elaborador do contrato e aquele que o utiliza no mercado de consumo [...] devem ter em conta o seu dever próprio de informar, que inclui o dever de redação clara e com destaque, além do dever de considerar a condição leiga do outro, evitando dubiedades na redação contratual (MARQUES, 2006, p. 229).

Claudia Lima Marques (2006, p. 646) afirma que "o dever de informar passa a representar, no sistema do CDC, um verdadeiro dever essencial, dever básico [...] para a harmonia e transparência das relações de consumo".

Com relação as fintechs esse princípio é essencial, haja vista a relação de consumo se dá através da internet, no qual o produto ou serviço somente é visualizado pelo consumidor por meio de imagens (fotos, desenhos, esboços, croqui, planta) e ou descrições textuais dispostos, e que em muitas vezes não retratam a realidade física, técnica e informacional.

Outro aspecto de suma relevância cinge-se no tratamento, manutenção e guarda das informações do consumidor, visto que são protegidas constitucionalmente pelo sigilo de dados, bem como pelo Marco Civil da Internet, que reforçou a proteção à privacidade e à intimidade de dados na rede.

Desta forma, conforme exposto alhures, o princípio da informação é um dever básico para a harmonia e transparência das relações de consumo.

\subsubsection{Princípio da Transparência}

O artigo $4^{\circ}$ do Código de Defesa do Consumidor traz outro princípio de suma importância na relação consumerista com as fintechs, o princípio da transparência que trata do amparo à informação na relação de consumo, determinado a forma como a informação deve ser prestada ao consumidor no ato da contratação. 
Na relação negocial a informação ao consumidor deve ser clara, ostensiva, precisa e correta, com o fito a sanar quaisquer dúvidas e garantir o equilíbrio contratual entre as partes contratantes.

Nesse aspecto, Claudia Lima Marques (2006, p. 594) aponta como ideia central do princípio da transparência:

[...] possibilitar a aproximação contratual mais sincera e menos danosa entre consumidor e fornecedor. Transparência significa informação clara e correta sobre o produto a ser vendido, sobre o contrato a ser firmado, significa lealdade e respeito nas relações entre fornecedor e consumidor, mesmo na fase pré-contratual, isto é, na fase negocial dos contratos de consumo.

Nota-se que o princípio da transparência encontra-se intimamente ligado ao princípio da informação, impondo a qualificação das informações prestadas ao consumidor mesmo durante as tratativas, na chamada fase pré-contratual, bem como durante todo o negócio jurídico.

O princípio da transparência ainda atua como um reflexo da boa-fé exigida aos agentes contratuais, que devem agir com transparência, prestando todas as informações de forma ampla, clara e objetiva ao consumidor, sempre pautando-se a qualidade da informação com lealdade, sinceridade e respeito.

\subsubsection{Princípio da Confiança}

No comércio eletrônico, um dos elementos importantes é a confiança do consumidor nesse novo mercado tecnológico. Noutra ponta, o consumidor vislumbra uma variedade de ofertas de produtos e serviços, obtendo diversas vantagens por adquirir em uma fintech por um preço bem mais econômico do que o mesmo de um produto ou serviço no estabelecimento físico do fornecedor; mais a mais, sente-se inseguro em arriscar fornecer seus dados nesse ambiente, o número do cartão de crédito, por exemplo, ou de não receber o contratado após o pagamento efetuado (SILVA; DOS SANTOS, 2013, p. 46).

Para Claudia Lima Marques (2004, p. 32, grifos no original), o princípio da confiança é um novo paradigma no contrato de consumo eletrônico, em suas palavras "confiar é acreditar (credere), é manter, com fé (fides) e fidelidade, a conduta, as escolhas e o meio; confiança é aparência, informação, transparência, diligência e ética no exteriorizar vontades negociais". 
Para a autora, a era digital desencadeou a "segunda crise do contrato", em virtude da despersonalização extrema oriunda dos contratos em massa de adesão e dos contratos firmados no meio eletrônico, o qual se verifica uma "desumanização do contrato" (MARQUES, 2004, p. 65).

Com efeito, a confiança é ponto fulcral nas relações de comércio eletrônico, impondo deveres anexos específicos, isso porque, diferentemente do que ocorre no mundo real, no qual aferível a da teoria da aparência, "aqui, a própria aparência se desmaterializou restando, apenas, a transparência, dado ou informação de um texto contratual complexo, rápido e especializado" (SILVA; DOS SANTOS, 2013, p. 46).

Assim, "aquele que utiliza o meio eletrônico e cria a aparência de que este pertence a sua esfera de interesses arca com os riscos e os ônus de demonstrar o contrário" (LORENZETTI, 2004, p. 293).

Nesse compasso, considerando-se o princípio da confiança imanente a todo o Direito, segue as palavras de Michael César Silva (2013, p. 46):

[...] o fornecedor, para a mantença de sua credibilidade no meio eletrônico, deve buscar conquistar a confiança do consumidor, através da observância às regras de boa conduta, colaboração, equilíbrio contratual, respeito às leis consumeristas e aos consumidores enquanto pessoa de direito e agente econômico. Nessa esteira, ao Direito cabe prover ampla informação e educação à sociedade de consumo, sempre inovando suas normas e evoluindo como Ciência que acompanha o avanço social e tecnológico.

Desse modo, as relações negociais que envolvem as fintechs restam guarida no princípio da confiança, e, cabe as partes da relação negocial zelarem pelo seu cumprimento, tendo em vista a desumanização dos contratos nesse ambiente.

\subsection{Da Responsabilidade Civil da Fintech}

Em virtude do avanço tecnológico que ambiente virtual proporciona o consumidor encontra-se sujeito a outros elementos, que podem de alguma forma afetar o processo de contratação via Internet, registra-se a ação de maliciosos programas de computador disseminados na Internet: vírus, spywares, backdoors, keyloggers, worms, dentre outros danos cometidos por hackers e crackers.

Nessa esteira, o consumidor que contrata a fintech possui no instituto da responsabilidade civil a garantia de reparação de eventual dano que venha a sofrer pela violação de um dever jurídico a que se obrigue o fornecedor. 
A responsabilidade foi disciplinada no Código de Defesa do Consumidor, em seus artigos 12 e 14, vejamos:

Art. 12. O fabricante, o produtor, o construtor, nacional ou estrangeiro, e o importador respondem, independentemente da existência de culpa, pela reparação dos danos causados aos consumidores por defeitos decorrentes de projeto, fabricação, construção, montagem, fórmulas, manipulação, apresentação ou acondicionamento de seus produtos, bem como por informações insuficientes ou inadequadas sobre sua utilização e riscos.

[...]

Art. 14. O fornecedor de serviços responde, independentemente da existência de culpa, pela reparação dos danos causados aos consumidores por defeitos relativos à prestação dos serviços, bem como por informações insuficientes ou inadequadas sobre sua fruição e riscos. (BRASIL, 1990)

Inspirado na moderna legislação consumerista da época, o Código de Defesa do Consumidor adotou a responsabilidade objetiva do fornecedor pelos "danos que cause no mercado de consumo, o fornecedor - cujo conceito é amplo para compreender todos que disponibilizam produtos ou serviços com habitualidade, mediante remuneração - responde, sem culpa, pelos danos sofridos pelos consumidores" (BRAGA NETTO, 2011, p.118).

Desse modo, o consumidor no instituto da responsabilidade civil encontra garantia de reparação de eventual dano que venha a sofrer pela violação de um dever jurídico que obrigue a fintech fornecedora.

\subsection{Do Direito de Arrependimento}

O direito de arrependimento está previsto no artigo 49 do Código de Defesa do Consumidor, sendo aplicado quando se efetuam fornecimento de produtos e serviços fora do estabelecimento empresarial.

Art. 49. O consumidor pode desistir do contrato, no prazo de 7 dias a contar de sua assinatura ou do ato de recebimento do produto ou serviço, sempre que a contratação de fornecimento de produtos e serviços ocorrer fora do estabelecimento comercial, especialmente por telefone ou a domicílio.

Parágrafo único. Se o consumidor exercitar o direito de arrependimento previsto neste artigo, os valores eventualmente pagos, a qualquer título, durante o prazo de reflexão, serão devolvidos, de imediato, monetariamente atualizados. (BRASIL, 1990)

A ratio da norma é que quando o consumidor adquire o produto ou o serviço fora do estabelecimento empresarial, fica ainda mais vulnerável na relação instituída com o fornecedor, assim, as negociações com as fintechs se enquadram nesse contexto.

Nesse sentido o autor, José Carlos Maldonado de Carvalho (2008, p. 135-136, grifos do autor), vejamos: 
O Código ao referir-se às contratações "especialmente por telefone ou a domicílio", o fez de modo exemplificativo (numerus apertus), razão pela qual sujeita-se também ao direito de arrependimento toda e qualquer contratação celebrada fora do estabelecimento comercial, o que inclui, ipso facto, as que venham a ser realizadas através de fax, videotexto, mala direta, e-mail, em domicílio, etc.

O Decreto n. 7.962, de 15 de março de 2013, regulamentou as contratações e o

direito de arrependimento no comércio eletrônico assertivamente em seu artigo $5^{\circ}$, verbis:

Art. $5^{\circ} \mathrm{O}$ fornecedor deve informar, de forma clara e ostensiva, os meios adequados e eficazes para o exercício do direito de arrependimento pelo consumidor.

$\S 1$ o O consumidor poderá exercer seu direito de arrependimento pela mesma ferramenta utilizada para a contratação, sem prejuízo de outros meios disponibilizados.

$\S 20 \mathrm{O}$ exercício do direito de arrependimento implica a rescisão dos contratos acessórios, sem qualquer ônus para o consumidor.

§ 3o O exercício do direito de arrependimento será comunicado imediatamente pelo fornecedor à instituição financeira ou à administradora do cartão de crédito ou similar, para que:

I - a transação não seja lançada na fatura do consumidor; ou

II - seja efetivado o estorno do valor, caso o lançamento na fatura já tenha sido realizado.

$\S 4$ o O fornecedor deve enviar ao consumidor confirmação imediata do recebimento da manifestação de arrependimento. (BRASIL, 2013)

Dessa maneira, aos consumidores que adquirirem produtos e usufruírem de serviços das fintechs, o seu direito a arrependimento encontra-se possível e disciplinado pela legislação consumerista.

\section{CONCLUSÃO}

Diante de todo o exposto e do amplo debate, pode-se concluir que fintech produziu uma revolução para o comércio, fomentando a economia ao movimentar bilhões de reais em serviços, que antes eram atinentes aos Bancos Tradicionais, em virtude do amplo acesso à rede mundial, que deixou de ser um requinte das classes sociais mais elevadas, as fintechs tornaram-se populares e encontrou ancora nas necessidades humanas de consumo em um mundo imediatista e globalizado.

Noutro ponto, em contrapartida aos benefícios apresentados pelas fintechs surgem também novas formas de agressão ao direito do consumidor, requerendo que haja um monitoramento permanente e modulação da regulamentação legal de forma a coibir a violação de dados, os excessos da publicidade e do marketing agressivo, cyber ataques, e, também, a omissão ou imprecisão de informações da oferta e dos contratos.

Nesse limbo, em virtude da inércia do legislativo, a resolução de conflitos no Judiciário e nos órgãos e associações de proteção e defesa do consumidor são resolvidos na 
interpretação doutrinária e jurisprudencial dos atuais diplomas legais, o Código de Defesa do Consumidor, e subsidiariamente, o Código Civil, não se olvidando das demais leis que compõe o sistema de proteção ao consumidor no Brasil. Todavia, as incertezas na aplicação das referidas leis que não alcançam tecnicamente todas as novas situações fáticas desse meio (virtual) causam desconforto e insegurança maior para os sujeitos da relação jurídica de consumo em litígio.

Para tanto, é necessária uma modernização do legislador, para que compreenda o ambiente eletrônico e, cognitivamente, possa produzir norma especial que atinja toda a seara do Direito Eletrônico.

$\mathrm{Na}$ ótica da segurança e à confiança nas negociações com as Fintechs, elas têm sido demonstradas nos altos índices de contratações realizadas, cada vez mais firmadas pela utilização de ferramentas tecnológicas, como a assinatura digital e certificação digital, o qual estão se consolidando como indispensáveis ao cotidiano das pessoas.

Noutro ponto, não podem, as fintechs, fazerem do ambiente eletrônico um meio de manipulação, através do marketing direto e agressivo de produtos e serviços, da vontade do consumidor, tendo em vista a vulnerabilidade informacional, técnica, jurídica, econômica. Nesse contexto, não é por um click ou toque de forma impensada que poderá ter o consumidor uma assinatura de um contrato indesejado, o qual se encontrará responsável contratualmente.

Por fim, na atual estrutura principiológica do Direito do Consumidor verifica-se que princípios como a boa-fé objetiva, da vulnerabilidade do consumidor, da informação, da transparência e da confiança são plenamente aplicáveis como diretrizes da conduta das partes na relação de consumo com as fintechs. Dos deveres jurídicos, sobressaem os deveres anexos da boa-fé objetiva que, se violados geram o inadimplemento do contrato - violação positiva do contrato -, e, por conseguinte, a responsabilidade objetiva, daquele que lhe deu causa.

\section{REFERÊNCIAS}

ALEXY, Robert. Teoria dos direitos fundamentais. $2^{\text {a }}$ ed. São Paulo: Malheiros, 2015. 
ÁVILA, Humberto. Teoria dos princípios. Da definição à aplicação dos princípios jurídicos. $8^{\mathrm{a}}$ ed. São Paulo: Malheiros, 2008.

BARROSO, Luis Roberto. Fundamentos Teóricos e Filosóficos do Novo Direito Constitucional Brasileiro - pós modernidade, teoria crítica e pós-positivismo, Rev. Da EMERJ, v. 4, n.15, 2001.

BARROSO, Luiz Roberto; BARCELlOS, Ana Paula de. Começo da história: a nova interpretação constitucional e o papel dos princípios no direito brasileiro. Revista de Direito Administrativo, Rio de Janeiro, vº. 232, abril/junho, 2003.

BENJAMIN, Antônio Herman V.; MARQUES, Claudia Lima; BESSA, Leonardo Roscoe. Manual de Direito do Consumidor. $2^{\text {a }}$ ed., São Paulo: Revista dos Tribunais, 2008.

BRAGA, Fábio Almeida. As Fintechs e a necessidade de regulação. Disponível em <http://www.demarest.com.br/pt-br/publicacoes/Artigos/pt/as-fintechs-e-a-necessidade-deregulacao.pdf> Acesso em 24 de junho de 2017.

BRAGA NETTO, Felipe Peixoto. Manual de direito do consumidor: à luz da jurisprudência do STJ. $6^{\text {a }}$ Ed., Salvador: Juspodivm, 2011.

BRASIL. Supremo Tribunal Federal. Ação Direta de Inconstitucionalidade $\mathbf{n}^{\mathbf{0}} 2591$. Ministro Carlos Velloso. 2001. Disponível em: <http://www.stf.jus.br/portal/peticaoInicial/verPeticaoInicial.asp?base=ADIN\&s1=2591\&pro cesso=2591>. Acesso em 25 de março de 2018.

BRASIL. Código de Defesa do Consumidor (1990). Lei $\mathrm{n}^{\circ}$ 8.078, de 11 de setembro de 1990. Brasília: Congresso Nacional, 1990.

BRASIL. Constituição (1988). Constituição da República Federativa do Brasil. Brasília: Senado Federal, 1988.

BRASIL. Portaria CVM/PTE/N ${ }^{\circ}$ 105, de 7 de junho de 2016. Disponível em: <http://www.cvm.gov.br/export/sites/cvm/decisoes/anexos/2016/20160607/PORTARIA105.pdf.> Acesso em 25 de março de 2018.

BRASIL. Decreto n. 7.962, de 15 de março de 2013. Brasília: Presidência da República, 2013.

CARVALHO, José Carlos Maldonado de. Direito do consumidor: fundamentos doutrinários e visão jurisprudencial. 3. ed. Rio de Janeiro: Editora Lumen Juris, 2008

GARCIA, Leonardo de Medeiros. Direito do Consumidor: Código comentado e jurisprudência. 4. ed. Niterói, RJ: Impetus, 2008.

GIANCOLI, Brunno Pandori; ARAUJO JÚNIOR, Marco Antônio. Direito do consumidor: difusos e coletivos. São Paulo: Revista dos Tribunais, 2009. 
GRAU, Eros Roberto. A Ordem Econômica na Constituição de 1988. $6^{\text {a }}$ ed, rev. e atual. São Paulo: Malheiros, 2001.

GRINOVER, Ada Pellegrini et al. Código brasileiro de defesa do consumidor: comentado pelos autores do anteprojeto. 9. ed. Rio de Janeiro: Forense Universitária, 2007.

GUIA BOLSO. Entenda o que é Fintech. Disponível em <https://blog.guiabolso.com.br/2016/05/10/entenda-o-que-e-fintech/>. Acesso: 24 de março de 2018.

HORN, Guilherme. Os bancos serão necessários no futuro? Disponível em <http://link.estadao.com.br/blogs/seu-bolso-na-era-digital/os-bancos-serao-necessarios-nofuturo/>. Acesso em 10 de janeiro de 2018.

LORENZETTI, Ricardo L. Comércio eletrônico. São Paulo: Revista dos Tribunais, 2004.

MARQUES, Claudia Lima; BENJAMIN, Antônio Herman V.; MIRAGEM, Bruno. Comentários ao Código de Defesa do Consumidor. $3^{\text {a }}$ ed. São Paulo: RT, 2010.

MARQUES, Claudia Lima. Confiança no comércio eletrônico e a proteção do consumidor: um estudo dos negócios jurídicos de consumo no comércio eletrônico. São Paulo: Revista dos Tribunais, 2004.

NAJJARIAN, Ilene Patrícia de Noronha. Fintech: Novo Desafio Regulatório. Revista de Direito Bancário e do Mercado de Capitais, vol. 74/2016, p. 33 - 49, Out - Dez / 2016.

NISHIYAMA, Adolfo Mamoru. A proteção constitucional do consumidor. Rio de Janeiro: Forense, 2002.

NUNES, Rizzatto. Comentários ao Código de Defesa do Consumidor. $8^{\mathrm{a}}$ ed., São Paulo: Saraiva. 2015.

RÊGO, Werson Franco Pereira; RÊGO, Oswaldo Luiz Franco. O Código de Defesa do Consumidor e o Direito Econômico. Revista Jus Navigandi, ISSN 1518-4862, Teresina, ano 7, n. 55, 1 mar. 2002. Disponível em: <https://jus.com.br/artigos/2801>. Acesso em 23 março de 2018.

RIBEIRO, Lucas de Mello. Uma visão sobre as fintechs e sua legislação. Disponível em $<$ http://www.migalhas.com.br/dePeso/16,MI260587,71043-

Uma+visao+sobre+as+fintechs+e+sua+legislacao>. Acesso em 24 de março de 2018.

ROSENVALD, Nelson. Dignidade humana e boa-fé no Código Civil. São Paulo: Saraiva, 2005 . 
SILVA, Michael César Silva; DOS SANTOS, Wellington Fonseca. O Direito do Consumidor nas Relações de consumo virtuais. Revista Eletrônica de Direito do Centro Universitário Newton Paiva. nº. 21, vº. 02/2013, p. 39-55, ISSN 16788729.

TARTUCE, Flávio. Função Social dos Contratos: do Código de Defesa do Consumidor ao Código Civil de 2002. 2.ed., São Paulo: Método, 2007.

TAVARES, André Ramos. Direito constitucional econômico. $3^{\mathrm{a}}$ ed. Rio de Janeiro: Forense; São Paulo: Método, 2011. 